RESENHAS 


\section{ANTUNES, António Lobo. Sôbolos rios que vão. Lisboa: Dom Quixote, 2010.199 p.}

Cid Ottoni Bylaardt Universidade Federal do Ceará - CNPq

ôbolos rios que vão (2010), vigésimo-segundo romance de António Lobo Antunes, é uma narrativa cujos eventos giram em torno da memória de um doente de câncer que se encontra em um quarto de hospital em Lisboa, um certo senhor Antunes, ou Antoninho. O enunciado está compreendido entre os dias 21 de março e 4 de abril de 2007, totalizando quinze capítulos, cada um deles tendo uma data como título, o que corresponde a quinze dias seguidos de enunciação. Considerando que o autor teve um câncer diagnosticado no primeiro semestre de 2007, do qual hoje é dado como curado, não faltam os que pretendem descobrir triunfalmente elementos autobiográficos na narrativa, o que nos parece uma atitude tão irrelevante quanto inconsistente.

A voz predominante é de um narrador anônimo de terceira pessoa, fato que dificulta classificar a narrativa como um diário, no sentido tradicional do gênero, o que preserva a constatação de que as narrativas de Antunes são inclassificáveis. Embora haja um locutor de terceira pessoa, o que se espera desse autor singular, e de fato ocorre, é que não haja um enunciador onipotente, condutor, a guiar a escritura por um caminho diegético seguro. Assim, a locução do próprio doente se intromete na fala anônima, bem como a do avô, às vezes a de um enfermeiro, e mais alguns outros personagens. Por outro 
lado, a predominância da voz narrativa anônima não impede que ela seja hesitante, alinear, irresoluta.

Outro aspecto que chama a atenção de imediato é o título, uma apropriação do primeiro verso das Redondilhas de Babel e Sião de Camões, por sua vez inspiradas no salmo 136, "Junto aos rios de Babilônia", Livro de salmos do Antigo Testamento, em que David narra o exílio dos hebreus cativos em Babilônia. No poema de Camões, um enunciador em primeira pessoa constrói as alegrias de seu passado em Sião em confronto com o sofrimento do presente em Babilônia.

Embora o assunto, o gênero, a forma, a linguagem do poema e do romance sejam completamente diferentes, podem-se estabelecer algumas aproximações entre os dois, principalmente em algumas concepções de escritura e memória que o locutor camoniano emite e que a narrativa de Lobo Antunes desdobra e transforma. Ao declarar, por exemplo, que "Bem são rios estas águas, / com que banho este papel" (versos 51 e 52), o enunciador de Camões alude a uma imagem que pode estender-se ao texto antuniano: a de que a escritura é levada e lavada pelas águas irreprimidas do rio, compondo um entrelaçamento confuso entre presente e passado, a delinear pela linguagem um sofrimento multifacetado. Também os versos 211 a 216 seguintes aludem à construção da memória, determinante da escritura do romance:
Mas ó tu, terra de Glória, se eu nunca vi tua essência como me lembras na ausência?
Não me lembras na memória, senão na reminiscência.

Os versos sugerem que não há memória, há reminiscência, e a própria recordação é problematizada pelo fato de que quem lembra não conhece a essência da coisa lembrada. Temos, 
assim, uma verdade imemorial, que não é construída como resgate, mas como invenção.

Tanto o título do romance, que raras vezes em Lobo Antunes apresenta, como aqui, uma relação tão direta com a matéria narrada, quanto as reminiscências de águas que banham um papel em que se escreve desembocam de maneira incontornável na ideia do rio, ou dos rios, relacionada à escritura e à memória. $\mathrm{O}$ rio Mondego é presença constante nas memórias do personagem, sob várias figurações. Uma delas, que aparece com certa insistência, é a da nascente do rio, que o pai lhe mostrara em algum momento do passado e que parece ser o início de um caminho a se percorrer sobre os rios da escritura, inicialmente como tentativa vã de buscar esse ponto inicial, "um fiozito entre penedos quase no alto da serra", 1 a nascente da própria lembrança, um "fiozito", nada mais.

Essa busca insistente da nascente do Mondego força uma reflexão sobre o andamento originário da linguagem poética, sua fala singular, inabitual, aquilo que não se desgastou, que preserva o encanto da descoberta, como tenta dizer a poesia de Manoel de Barros, que se inclui entre as leituras de Lobo Antunes. $\mathrm{O}$ escritor tem declarado sua intenção de reduzir a escrita ao osso, e a ideia do osso nos remete ao curioso poema "Escova", de Manoel de Barros, em que o enunciador manifesta sua perplexidade ante os arqueólogos escovadores de osso, e põese a escovar palavras, para resgatar suas significâncias primitivas, que ora associamos à busca da nascente do Mondego, no romance.

Nascente, osso, origem: os termos não querem ser precisos, possivelmente porque não querem estabelecer-se, condenaremse à verdade. Talvez seja essa a essência da arte, da poesia:

${ }^{1}$ ANTUNES, 2010, p. 16. 
buscar essa verdade originária que nenhum conceito metafísico poderá definir, a busca do momento não contaminado em que a linguagem está diante do artista para se fazer poesia. É uma ideia cara a Heidegger, a Blanchot, a Foucault, a Barthes, a Agamben, enfim, a muitos dos que pensam a literatura, dos que refletem sobre a poesia.

A nascente, todavia, não pode ser encontrada verdadeiramente, e a narrativa segue sôbolos rios. $\mathrm{O}$ avô do personagem hospitalizado lhe deseja que repouse e que embarque na memória do sonho: "talvez sonhes com a nascente do Mondego e caminhes juntamente com o rio numa névoa de luz". ${ }^{2}$ Não se pode deixar de relacionar esse caminhar com o rio à escritura, e assim são frequentes as referências à descida do Mondego, rio que ganha força em seu deslizar no sentido da foz, mas um deslizar trôpego, indiscernível como a memória, "difícil de distinguir no nevoeiro do Mondego", 3 inelutável como seu clamor pela vida, e evidentemente pela escritura: "levem-me com vocês a caminhar sobre os rios", ${ }^{4}$ ou confiante como sua declaração à mãe: "vou com os rios mãe", ${ }^{5}$ e então julgava que "descia sobre os rios a caminho do mar", ele que já sabia o que precisava saber, independentemente do que o pai podia lhe ensinar: "bastava a certeza de chegar à foz". ${ }^{6}$

Ao mesmo tempo, a nascente não é algo que se processa e se estabelece como ato de vir à luz e acontecer: "a humidade feita de líquenes do Mondego que não termina de nascer numa

${ }^{2}$ ANTUNES, 2010, p. 20.

${ }^{3}$ ANTUNES, 2010, p. 26.

${ }^{4}$ ANTUNES, 2010, p. 65.

${ }^{5}$ ANTUNES, 2010, p. 82.

${ }^{6}$ ANTUNES, 2010, p. 83.

${ }^{7}$ ANTUNES, 2010, p. 32. 
falha de penhascos". ${ }^{7}$ Tanto nascer quanto morrer pertencem a um contínuo incessante: jamais se morre completamente, como nunca se nasce em definitivo. Assim, temos um doente de câncer que está a morrer todo o tempo e não morre como ser de escritura, uma vez que o relato termina com o senhor Antunes feito Antoninho na infância, a ouvir o canto da mãe, "sobre os rios a caminho da foz", ${ }^{8}$ sempre a caminho da foz, assim como as andorinhas jamais morrem, assim como a escritura nunca nasce e nem morre, assim como ele tropeça "carruagens adiante" no comboio que vai em direção à nascente, "a escapar do que levo comigo", 9 ou seja, a fugir do câncer na direção da serra, "que é da certeza de não morrer".${ }^{10}$ Como a pontuação de Lobo Antunes não é utilizada convencionalmente, a expressão que fala da incerteza da morte, ou da certeza da não-morte, tanto pode ser uma indagação, uma busca, quanto uma afirmação, como se não morrer equivalesse a uma viagem em sentido contrário. Isso nos faz pensar no sentido da escritura, tanto em termos de compreensão, de significação, quanto na acepção de orientação: que significa essa narrativa, para onde se dirige essa escritura? Em Lobo Antunes, essas perguntas não encontram respostas, ou pelo menos não encontram as mesmas respostas que se encontram nas narrativas convencionais. Como não faz sentido decifrar um sentido, a narrativa fica, como fica o personagem que se recusa a morrer: "mas não faz sentido eu morrer e por não fazer sentido fico".$^{11}$ Da mesma forma, "os nomes dos rios se esvaziaram de sentido", ${ }^{12}$ para

\footnotetext{
${ }^{8}$ ANTUNES, 2010, p. 199.

${ }^{9}$ ANTUNES, 2010, p. 48.

${ }^{10}$ ANTUNES, 2010, p. 48.

${ }^{11}$ ANTUNES, 2010, p. 53.

${ }^{12}$ ANTUNES, 2010, p. 133.
} 
que servem as palavras que designam os seres, principalmente seres fluidos, cuja sina é correr e correr sem que se lhes possa atribuir um sentido. Sim, mas o rio tem um sentido, sabe-se que se desloca para o mar, o personagem tem a certeza de que vai à foz, e ao chegar ao mar as possibilidades infinitas se abrem com a "barca bela que se vai deitar ao mar". ${ }^{13}$ Os versos da canção infantil aparecem no dia dois de abril: "a mãe cantava diante da máquina de costura e ele a acompanhá-la na enfermaria, recordava uns versos, não recordava outros", 14 e na ambiguidade de locução a barca bela da escritura, na voz do personagem e de sua mãe, desliza aos trancos em direção ao mar: "quem quer ver a barca bela e o resto dos versos perdido". ${ }^{15}$

Assim, temos onze capítulos, ou onze seções, em que há exposição, superposição, repetição, transformação, inversão, espelhamento, palinódia de fragmentos de memória. Entremeiamse, de um lado, o presente do personagem a morrer no leito do hospital, os enfermeiros a lhe aplicarem remédios e injeções, o médico do "pingo no sapato" a afligi-lo com seu discurso da ciência; e de outro, o passado em momentos pouco nítidos, o menino a percorrer o oito na bicicleta, o hotel dos ingleses da mina de volfrâmio, a harpa de dona Irene, as frases feitas da avó, o jornal do avô, a vaidade da mãe, a luxúria do pai a molestar a empregada, a nascente do Mondego, a carroça do Virgílio, o senhor Hélio, amigo do avô, o colega gordo que lembrava catorze nomes de rio e ele nenhum, as andorinhas que não morrem, o gato existente-não-existente e muitas outras em adição.

${ }^{13}$ ANTUNES, 2010, p. 169.
${ }^{14}$ ANTUNES, 2010, p. 169.
${ }^{15}$ ANTUNES, 2010, p. 196. 
E assim como a barca bela busca seu rumo pelos meandros dos rios que vão, a escritura de Lobo Antunes tenta buscar seu sentido nos depoimentos, recordações, esquecimentos, sofrimentos das vozes que enunciam um discurso doente, que não se remedeia, que não se cura jamais porque não pode trazer o conforto do ato de compreender. E tanto a barca bela quanto a escritura vão dar ao mar, ao seu enorme, ao seu belo silêncio infinito que nada esclarece.

Coimbra, 13 de abril de 2011 